\title{
Study of Radiant Smoldering Ignition of Plywood Subjected to Prolonged Heating Using the Cone Calorimeter, TGA, and DSC
}

\author{
JOSHUA SWANN ${ }^{1}$, JUDITHANN HARTMAN ${ }^{1}$, CRAIG BEYLER ${ }^{2}$ \\ ${ }^{1}$ United States Naval Academy \\ 572 Holloway Road \\ Annapolis, MD 21402 \\ ${ }^{2}$ Hughes Associates, Inc. \\ 3610 Commerce Drive, Suite 817 \\ Baltimore, MD 21227
}

\begin{abstract}
Maple plywood samples were heated in an oven at $180^{\circ} \mathrm{C}$ to a residual weight of $70 \%, 50 \%$, and $30 \%$ of the virgin weight. The virgin plywood and the thermally pretreated samples were tested in a cone calorimeter over the range of 6 to $15 \mathrm{~kW} / \mathrm{m}^{2}$ without the use of an ignitor. Tests were conducted until smoldering/glowing combustion was observed or for eight hours if ignition was not observed. The extent of thermal pretreatment of the plywood had no measurable effect on the minimum heat flux for smoldering ignition. At heat fluxes above the minimum for ignition, ignition times were reduced for thermally pretreated samples relative to virgin wood. This is consistent with the thermal pretreatment achieving the charring required as the first step in smoldering ignition and the reduction in thermal inertia resulting from charring. Samples of the virgin and pretreated wood were subjected to thermogravimetric analysis (TGA) and differential scanning calorimetry (DSC). The chemical kinetics analysis of the virgin and pretreated samples showed no change in the chemical mechanism. The thermal pretreatment simply resulted in the samples being further along the reaction pathway at the start of the ignition test. The results are not consistent with the formation of a more reactive char species commonly referred to in the fire investigation lore as "pyrophoric carbon."
\end{abstract}

KEYWORDS: smoldering, ignition, wood, self-heating

\section{INTRODUCTION}

There is a long standing hypothesis that wood subjected to prolonged heating will form a reactive char that enhances the ignitability of wood, often referred to as "pyrophoric carbon." The hypothesis dates back over a century and that history is well described by Cuzzillo [1] and more briefly described by Cuzzillo and Pagni [2]. The work of Cuzzillo and Pagni is among the few modern investigations of prolonged heating effects. Using oven tests of whole wood and of wood chips, Cuzzillo and Pagni found that chemical alterations caused by prolonged heating do not enhance the self-heating properties of wood, and that at low temperatures the pretreatment reduced the tendency for self-heating. They found that physical changes (charring) caused by prolonged heating facilitate self-heating of whole wood by creating substantial transverse permeability which enhances oxygen diffusion into the interior and reduces the thermal inertia.

In a recent paper Babrauskas, Gray and Janssens [3] reviewed the old literature and anecdotal fire incidents and concluded that prolonged heating can reduce the ignition temperature of wood. No laboratory work was included in investigation. The evidence cited in that paper for reductions in ignition temperature arose out of incident investigations rather than laboratory investigations. Interestingly, this paper did not include any citation or mention of the work of Cuzzillo and Pagni. Clearly, there has been very limited scientific study of the effects of prolonged heating on smoldering ignition and significant controversy remains.

There are a number of recent investigations of the radiative ignition of wood at low heat fluxes [4-10]. Bilbao et al. [4] studied a Mediterranean pine over a range of heat fluxes and wind velocities. Tests were conducted for $900 \mathrm{~s}$ and smoldering ignition was observed only at fluxes above $20 \mathrm{~kW} / \mathrm{m}^{2}$. Spearpoint and Quintiere [5,6] examined the minimum heat flux for piloted ignition of several wood species in the cone calorimeter. End grain exposures resulted in piloted ignition at heat fluxes as low as $8 \mathrm{~kW} / \mathrm{m}^{2}$, while along grain exposures required a higher heat flux of $12 \mathrm{~kW} / \mathrm{m}^{2}$ for piloted ignition. Only limited data was reported for smoldering ignition at low heat fluxes. For maple exposed to $12 \mathrm{~kW} / \mathrm{m}^{2}$, the time for glowing ignition was about an hour and piloted flaming ignition occurred $10 \mathrm{~min}$ later. Spearpoint also reported the 
observation of glowing ignition prior to flaming ignition for specimen subjected along the grain to heat fluxes less than $10 \mathrm{~kW} / \mathrm{m}^{2}$, but no data was provided. Surface temperatures at the time of glowing ignition were not reported. Boonmee and Quintiere [7-8] studied glowing and flaming ignition of wood in a vertical orientation when exposed to a radiant flux either along the grain or perpendicular to the grain using a cone calorimeter. Above $40 \mathrm{~kW} / \mathrm{m}^{2}$, flaming auto-ignition was observed, while below $40 \mathrm{~kW} / \mathrm{m}^{2}$, glowing was observed first. They reported glowing ignition within $2 \mathrm{~h}$ from a $10 \mathrm{~kW} / \mathrm{m}^{2}$ exposure and thus considered $10 \mathrm{~kW} / \mathrm{m}^{2}$ to be the critical heat flux for glowing ignition. Lim and Chew [9] studied piloted flaming ignition of Nyatoh hardwood and the same wood exposed to $250^{\circ} \mathrm{C}$ until a $50 \%$ weight loss was attained. At high heat fluxes, the pretreated and virgin wood ignition times were similar. At lower fluxes, the pretreated samples ignited more quickly, though the critical flux for ignition of the virgin wood was $10 \mathrm{~kW} / \mathrm{m}^{2}$, while the pretreated wood did not ignite below $12 \mathrm{~kW} / \mathrm{m}^{2}$. Ignition surface temperatures of pretreated wood were greater than the virgin wood. Gratkowski, Dempsey, and Beyler [10] studied the radiative smoldering ignition of maple plywood. The critical radiant flux was well predicted by self-heating theory. The critical surface temperature for ignition was determined to be $270^{\circ} \mathrm{C}$. Using detailed in-depth temperature measurements they showed that at radiant fluxes near the critical heat flux for smoldering ignition $\left(7.5 \mathrm{~kW} / \mathrm{m}^{2}\right)$, ignition occurs at depth within the charred portion of the wood sample. This contrasts with the interpretations of Boonmee and Quintiere [7,8] of smoldering ignition as a surface phenomenon and contrasts with the views of Babrauskas et al. [3] that self-heating is not involved in short term (minutes to hours) heating to ignition of wood.

The current work is motivated by recent work on smoldering radiative ignition of wood by Gratkowski, Dembsey, and Beyler [10]. This work provided a well characterized and well studied radiant smoldering ignition basis for investigating the effect of prolonged heating upon the subsequent smoldering ignition of wood. In this paper, we have measured the critical heat flux for radiative smoldering ignition, the ignition temperature and kinetic parameters of both virgin and pretreated wood (wood from the same sheet of material used by Gratkowski et al. [10]) in order to determine if there is any evidence for a change in the self-heating mechanism caused by prolonged pretreating. It was established by Gratkowski et al. [10] that radiant smoldering ignition of the surface of wood can be understood in terms of self-heating theory as described by Bowes [11]. Prior use of TGA and DSC by the authors [12] to study the effect of treatments of materials upon self-heating behavior confirm that these methods are able to diagnose changes in smoldering ignition behavior of practical importance. In that work the addition of cerium nitrate to cellulosic material was studied. The addition changed the minimum radiant heat flux for smoldering ignition to be reduced from $7.5 \mathrm{~kW} / \mathrm{m}^{2}$ to $3 \mathrm{~kW} / \mathrm{m}^{2}$ [13], and this reduction was qualitatively observable using TGA and DSC. While the TGA and DSC methods were highly diagnostic of changes in self-heating behavior, the kinetic constants so determined were not consistent with the results of classical oven test methods. As such, TGA and DSC methods should be used diagnostically and not as a substitute for the more time intensive oven methods of deducing self-heating constants for the prediction of criticality.

\section{PREPARATION OF WOOD SAMPLES}

Dry maple plywood samples $18 \mathrm{~mm}$ thick (the same material as used by Gratkowski et al. [10]) were cut into $100 \times 100 \mathrm{~mm}$ square pieces and oven heated at $180^{\circ} \mathrm{C}$ for up to a month to achieve varying degrees of thermal decomposition, resulting in residual weights of 30,50 , and $70 \%$ of the virgin weight. Residual weight of 30\% represents a fully charred sample. These samples were used without further treatment in the cone calorimeter experiments. Aliquots of the wood were ground (by sawing) or crushed by mortar and pestle to fine sawdust for TGA and DSC testing.

\section{IGNITION TESTING BY CONE CALORIMETER}

\section{Test Procedure}

The apparatus used for smoldering radiant ignition testing was the cone calorimeter (ASTM E 1354 [14]) without the use of the spark pilot source. Surface temperatures were measured during the test using an optical pyrometer. The cone heating coil was set to the temperature corresponding to a heat flux between 6 and $15 \mathrm{~kW} / \mathrm{m}^{2}$ and allowed to reach a steady output. The cone controller maintained the set temperature within $\pm 2^{\circ} \mathrm{C}$ resulting in an uncertainty of the heat flux of less than $2 \%$. Experiments proceeded until either smoldering followed with signs of burnout occurred or $8 \mathrm{~h}$ passed. No less than two samples were tested at 
each heat flux. Smoldering ignition was defined by visual observation of glowing in a darkened room, which generally corresponded to a surface temperature at or near $400^{\circ} \mathrm{C}$. Glowing appears in several different locations, along the edges of cracks, on the flat surfaces between cracks, or deep within the crevices of a crack. Glowing along the edges of a crack was usually a point source and often transitory, while glowing on the flat surfaces or within cracks was more likely to be an area affect and more persistent. The time, location, and type of glowing were recorded as well as any growth in the areas affected over time. Smoldering ignition was verified by post-test observation of significant consumption of the sample or the presence of residual white ash.

\section{Results}

The results for the ignition tests are summarized in Figs. 1 and 2. Figure 1 is a map of the ignitability of the samples as a function of heat flux and extent of pretreating. The minimum heat flux for ignition determined by Gratkowski et al [10] was $7.5 \mathrm{~kW} / \mathrm{m}^{2}$, determined by bracketing. This value is shown as a vertical dashed line at $7.5 \mathrm{~kW} / \mathrm{m}^{2}$. The grey area around this line is an estimate of the accuracy of the determination. The figure shows that the minimum heat flux for smoldering ignition is not affected by the extent of prolonged heating pretreatment. All of the data points at the boundary of ignition and no ignition were conducted in duplicate. The only data point where both ignition and no ignition were observed in the duplicates was at $7.5 \mathrm{~kW} / \mathrm{m}^{2}$ at $30 \%$ residual weight. This point is indicated as not ignitable in Fig. 1.

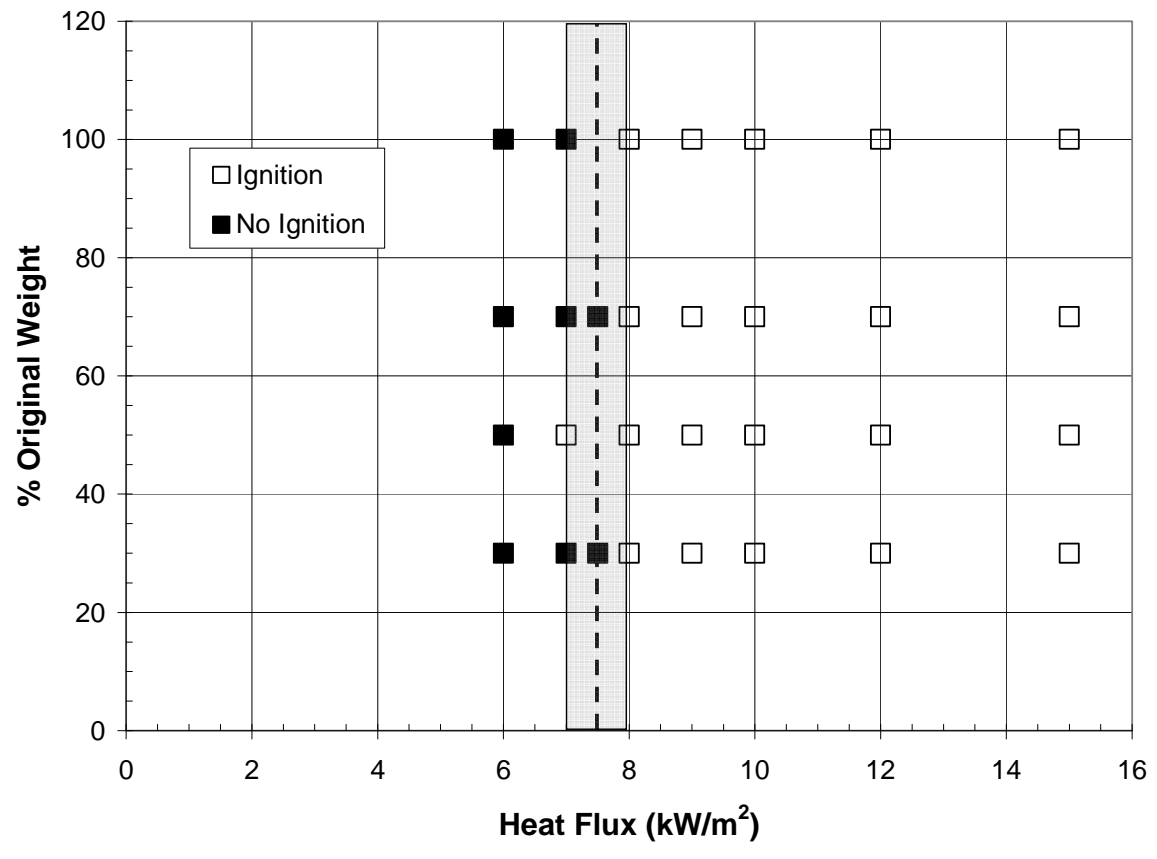

Fig. 1. Effect of prolonged heating upon smoldering ignition of samples over a range of residual weight percents.

It is of note that in the work of Cuzillo and Pagni [1,2], their determination of kinetic rates for pretreated wood was generally less than virgin wood. However, they found that at high temperatures $\left(\sim 250\right.$ to $\left.300^{\circ} \mathrm{C}\right)$ similar to our surface temperature for ignition, that the kinetic rates for virgin and pretreated wood were similar. This is consistent with our findings that the pretreatment of the wood had little effect on the minimum heat flux for ignition and the ignition temperature, which is dependent upon the kinetic rates as described by the surface ignition model developed by Bowes [11] and validated by Gratkowski et al. [10].

The times to ignition are shown in Fig. 2 using the common method of plotting radiant ignition data as motivated by the inert heating to an ignition temperature model. Figure 2 shows that for samples that were exposed to heat fluxes that were high enough to cause ignition, the time to ignition was markedly reduced by the prolonged heating pretreatment. The most notable reductions in time were observed at the $8 \mathrm{~kW} / \mathrm{m}^{2}$ exposure level, where the nearly four hour ignition time for the virgin wood was reduced to less than one 
hour for all of the samples subjected to prolonged heating. The reduction in heating time is expected since a smoldering ignition mechanism requires charring as the first step. Since this step has already been accomplished in whole or in part in the pretreated materials, the ignition can occur more quickly. In addition, the thermal inertia of the pretreated wood is lowered. Estimates of the reduction in thermal inertia using the constant heat flux solution for a thermally thick material based upon the initial temperature increase in the cone calorimeter test yielded reductions in thermal inertia in the range of 0.6 to 0.35 of the virgin thermal inertia. This is consistent with the measurements of Cuzzillo and Pagni [1,2]. Little reduction in thermal inertia and the ignition time was found with pretreatment to $30 \%$ relative to the $50 \%$ values. Reductions in thermal inertia due to reductions in weight are somewhat mitigated by material shrinkage.

The reduction in ignition time is a legitimate effect that can impact the ignitability of a material that is intermittently heated. As prior heating results in progressive charring of the material, the charred material can be ignited by a thermal exposure duration that could not have ignited the virgin material. This is consistent with the findings of Cuzzillo and Pagni $[1,2]$.

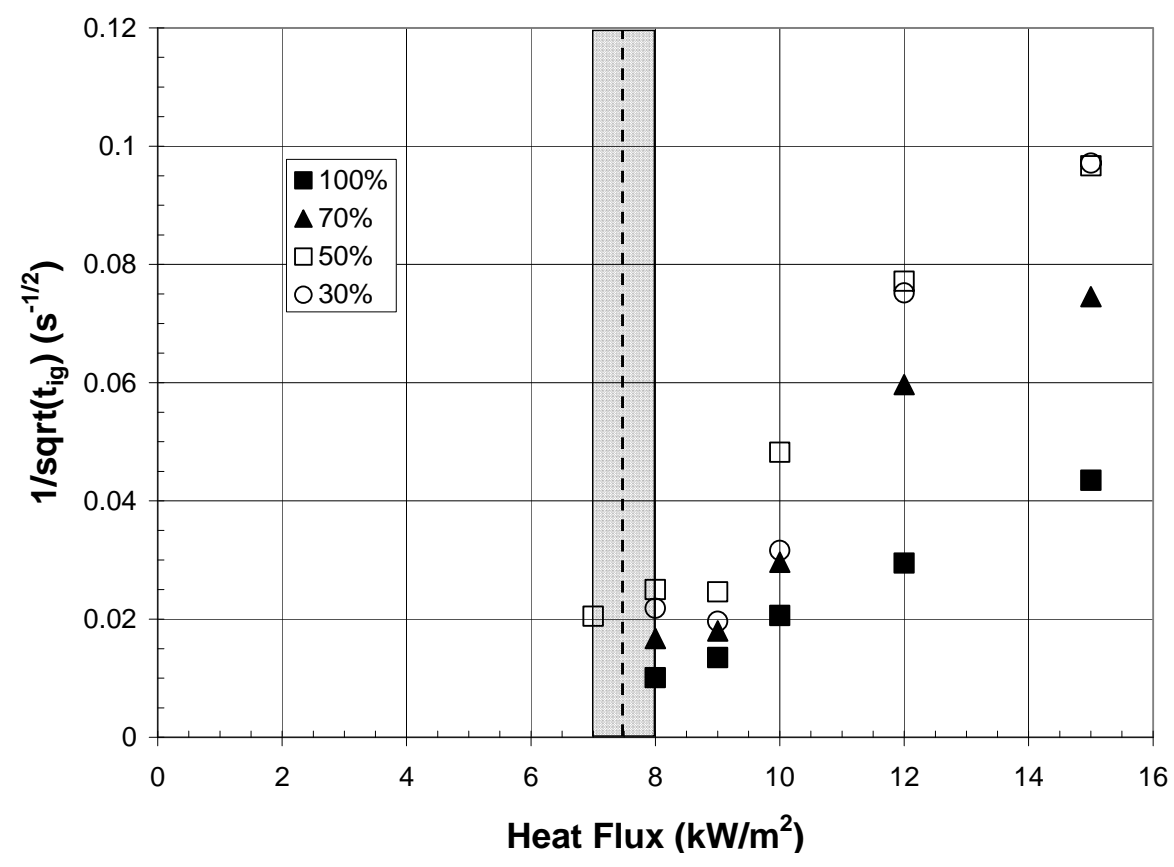

Fig. 2. Ignition data for smoldering ignition of the wood samples based upon the residual weight $\%$ of the pretreated samples. $100 \%$ refers to virgin material.

Representative surface temperature plots during ignition testing are illustrated in Fig. 3. At heat fluxes below the minimum heat flux for smoldering ignition, surface temperature traces are consistent with inert behavior of the sample. In the tests where no exothermic reaction occurred, surface temperatures are in the range of 240 to $270^{\circ} \mathrm{C}$ or less. At fluxes well above the minimum for smoldering ignition, surface temperatures quickly rise to the range of $400-500^{\circ} \mathrm{C}$. At fluxes modestly above the minimum heat flux for smoldering ignition, inert heating phase is followed by a change to upward curvature of the surface temperature with respect to time, with surface temperatures reaching $400^{\circ} \mathrm{C}$ or more. At fluxes at approximately the minimum for smoldering ignition, the surface temperature follows inert heating and then exhibits exothermic behavior. In tests where ignition does not occur, the exotherm ultimately terminates without reaching the critical point. In tests where ignition does occur, the classical self-heating thermal runaway (criticality) occurs. In several near- ignition tests $\left(70 \%\right.$ at 7 and $7.5 \mathrm{~kW} / \mathrm{m}^{2}$, and $30 \%$ at $7.5 \mathrm{~kW} / \mathrm{m}^{2}$ ), temperatures increased to $300-350^{\circ} \mathrm{C}$. These samples typically showed some localized ash deposits on the surface after the test, indicating that some combustion had occurred locally which was not sustained. Based upon the determination of the minimum heat flux for smoldering ignition and the surface temperature measurements, the critical surface temperature for smoldering ignition was not found to be a function of the extent of prior thermal decomposition/charring. 


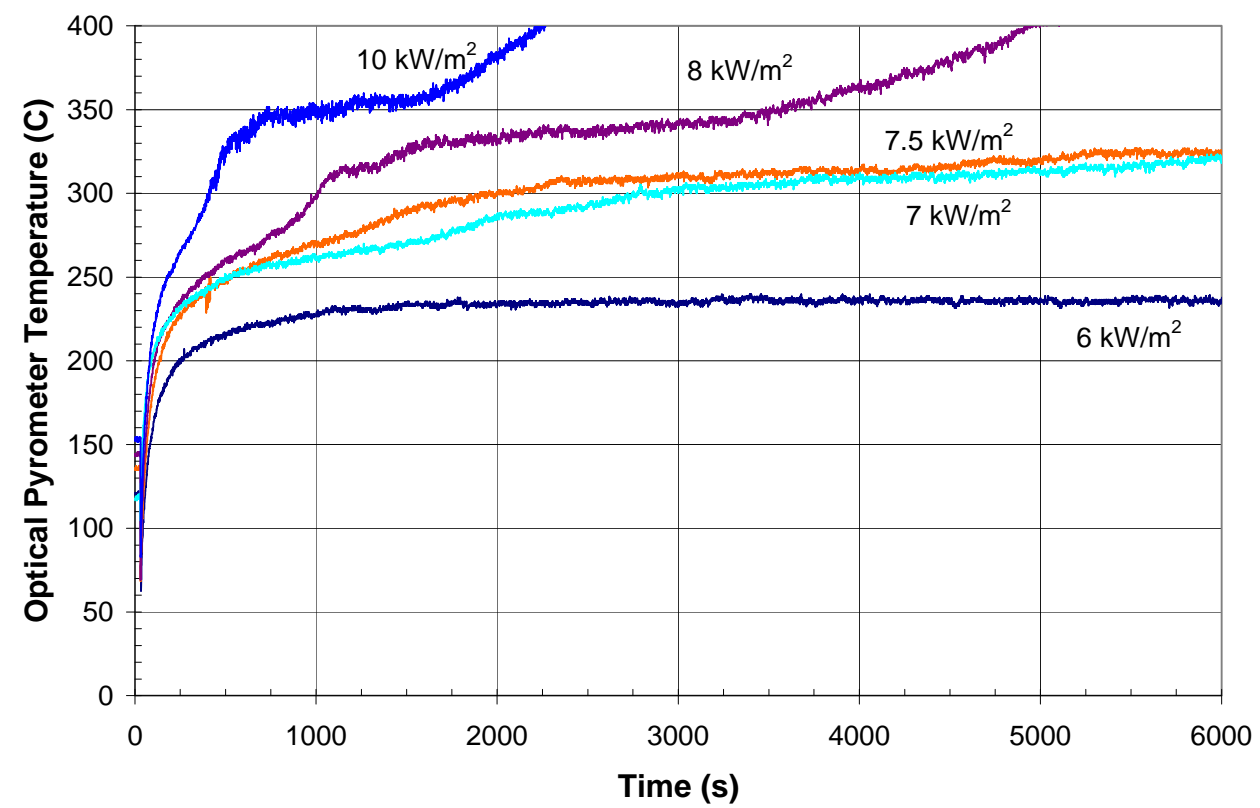

Fig.3. Surface temperature measurements for selected $70 \%$ residual weight tests. These surface temperature histories are representative of the behavior at all residual weights tested.

\section{THERMOGRAVIMETRIC ANALYSIS}

\section{Test Procedure}

Thermogravimetric analysis (TGA) was performed on a Thermal Analysis Model 2050 thermogravimetric analyzer following the procedures described in ASTM method E 1641-99 [15]. The instrument was calibrated with calcium oxalate. A representative sample of sawdust of approximately $5 \mathrm{mg}$ was placed on an open platinum pan and heated from 80 to $550^{\circ} \mathrm{C}$ using linear heating rates of $1,2,5$, and $10 \mathrm{~K} / \mathrm{min}$. Runs were conducted under dried air atmospheres with flow rates of $50 \mathrm{ml} / \mathrm{min}$. The data were analyzed according to ASTM method E 1641-99.

\section{Results}

The normalized TGA results for the virgin and pretreated wood samples are shown in Fig. 4. The data clearly show the presence of two distinct reactions for the virgin wood. The first reaction occurs during the decomposition of the first $70 \%$ of the weight (from approximately 250 to $350^{\circ} \mathrm{C}$ ) while the second reaction occurs during the decomposition of the last $30 \%$ of the weight (from approximately 350 to $500^{\circ} \mathrm{C}$ ). These results are consistent with previous TGA and DSC results. Rogers and Ohlemiller [16] showed that the combustion of cellulosic insulation (primarily ground wood pulp) took place in two overall reactions with the first reaction consuming approximately $65 \%$ of the weight and the second reaction consuming approximately $30 \%$. The specific chemical reactions that comprise these two peaks were not assigned, but both regions fit kinetic models that assumed that the diffusion of a reactant through a product layer was rate limiting. Rogers and Ohlemiller hypothesized that the first step comprised both oxidative and inert pyrolysis while the second peak contained the reactions that formed $\mathrm{CO}$ and $\mathrm{CO}_{2}$ from the more carbonaceous char. Other researchers have shown that the chemical reactions in the first step correspond primarily to the oxidation of cellulose and those in the second step include the oxidation of lignin, a lignin/polysaccharide complex, or other polysaccharides [17-21]. For each biopolymer studied, the mass loss is characterized by three stages of decomposition [21]:

1. up to about $150^{\circ} \mathrm{C}$ : loss of moisture content in an endothermic reaction;

2. between 150 and about $400^{\circ} \mathrm{C}$ : decomposition of the polymer with char formation and the evolution of gas (exothermic reaction); and

3. between 400 and about $500^{\circ} \mathrm{C}$ : combustion of the char (exothermic reaction). 


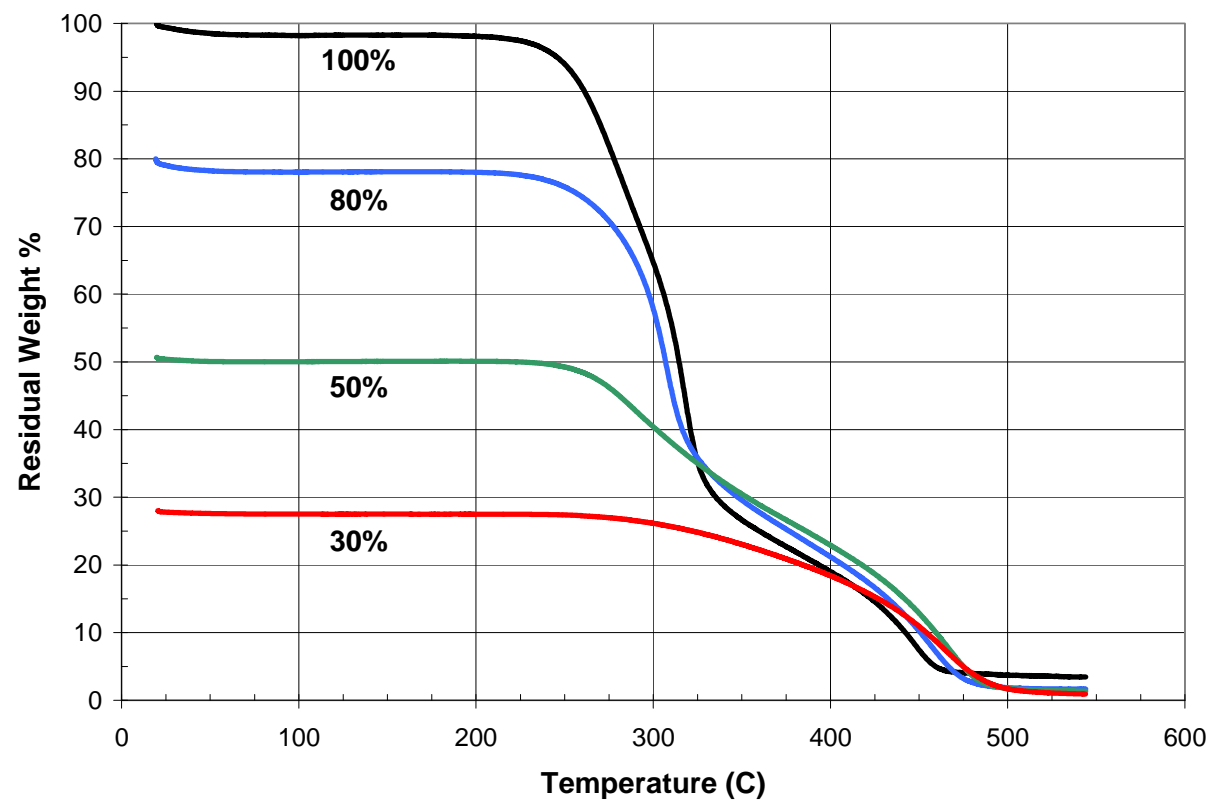

Fig. 4. TGA results for a $5^{\circ} \mathrm{K} / \mathrm{min}$ rate under dried air atmosphere. Weight \%'s are normalized by the virgin weight of the sample.

Although the observed two regions in the TGA are caused by the presence of different species in the wood, the stages in the combustion process for the each component is spread across the temperature ranges of the two observed regions. Since cellulose is the most active component, the kinetics of the reaction up to approximately $300^{\circ} \mathrm{C}$ is closely associated with the cellulose component while the kinetics at higher temperatures will include the other components of wood. The kinetics for the first three samples in this work (virgin wood, $80 \%$ and $50 \%$ wt wood) were measured below $300^{\circ} \mathrm{C}$ while the kinetics for the completely charred sample $(30 \mathrm{wt} \%)$ was measured at $319^{\circ} \mathrm{C}$.

The data also clearly show that the TGA data for the four wood samples represent a nested set of curves demonstrating that the same series of reactions are occurring in the prolonged moderate pretreating as in the oven. The virgin wood demonstrated the expected magnitude of the two reaction steps. The $80 \%$ and $50 \%$ samples show that progressively more of the first step has been completed in the oven while the $30 \%$ weight sample shows that all of the first step has been completed in the oven. If the prolonged moderate heating was indeed forming a "pyrophoric carbon" species, the TGA data above $300^{\circ} \mathrm{C}$ would be expected to diverge, not converge as shown in Fig. 4.

The activation energy, E, and Arrhenius pre-exponential factor were calculated from this data using the method described in ASTM E 1641-99 [15]. The temperatures at 10\% decomposition for four different heating rates $\left(1,2,5\right.$, and $\left.10{ }^{\circ} \mathrm{C} / \mathrm{min}\right)$ were determined and plotted as $\log$ heating rate, $\beta,\left({ }^{\circ} \mathrm{C} / \mathrm{min}\right)$ vs. 1000/T (K). The Arrhenius plots at 10\% decomposition are shown in Fig. 5.

The activation energy was calculated from the Arrhenius plots in an iterative fashion from Eq. 1.

$\mathrm{E}=-(\mathrm{R} / \mathrm{b})^{*} \Delta(\log \beta) / \Delta(1 / \mathrm{T})$

where $\mathrm{R}$ is the ideal gas constant, $\mathrm{b}$ is an approximation derivative provided by the ASTM method. The pre-exponential factor was calculated using the expression Eq. 2.

$\mathrm{A}=-\left(\beta^{\prime} / \mathrm{E}\right) * \mathrm{R}^{*} \ln (1-\alpha)^{*} 10^{\mathrm{a}}$

where $\beta^{\prime}$ is $5^{\circ} \mathrm{K} / \mathrm{min}$ (the median heating rate used), $\alpha$ is the percent decomposition, a is an approximation integral provided by the ASTM method. 


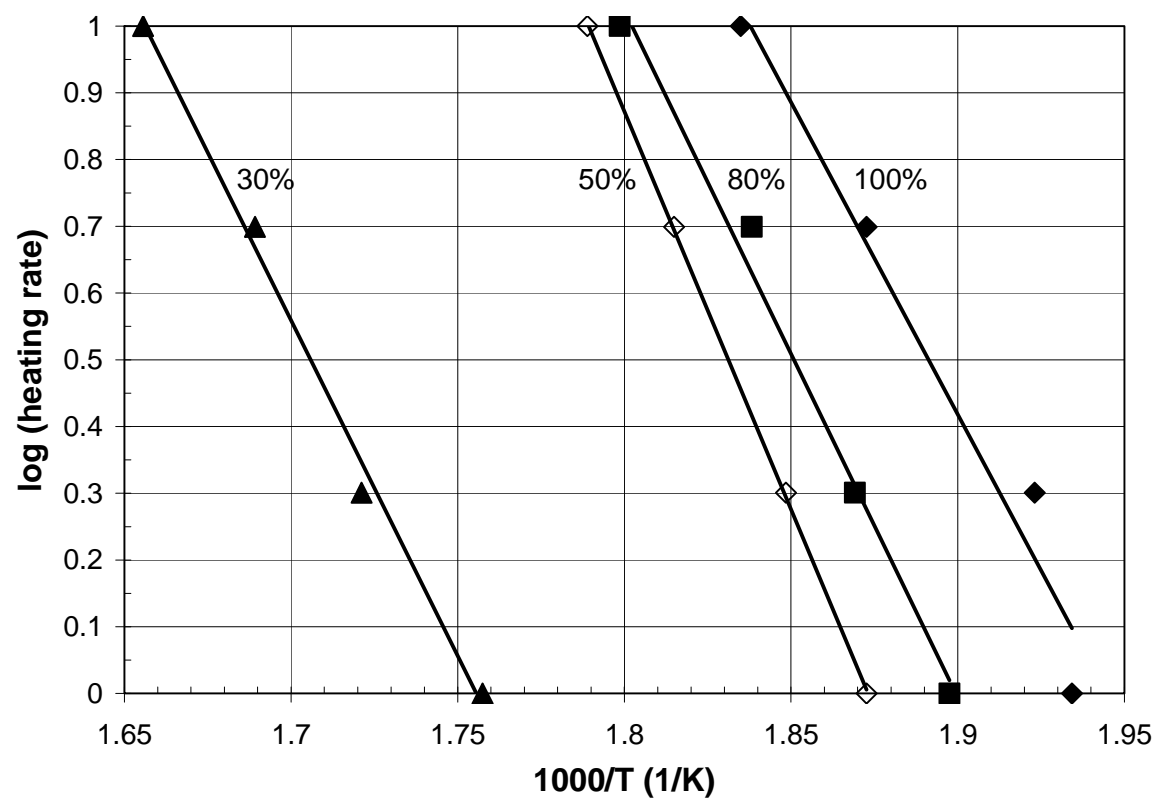

Fig. 5. The Arrhenius plots at $10 \%$ decomposition for the TGA data for virgin wood and $30 \%, 50 \%$ and $80 \%$ residual weight $\%$.

These results are summarized in Table 1. The standard deviations in Table 1 were calculated from the observed standard deviation of the data using standard propagation of error and do not include the inherent error introduced by the ASTM method.

The activation energies and the pre-Arrhenius constants increased consistently from $170 \mathrm{~kJ}$ and $1.2 \times 10^{15} \mathrm{~min}^{-1}$ for the virgin wood to $219 \mathrm{~kJ}$ and $3.9 \times 10^{19} \mathrm{~min}^{-1}$ for the $51 \%$ wood before dropping sharply to $182 \mathrm{~kJ}$ and $4.1 \times 10^{14} \mathrm{~min}^{-1}$ for the $30 \%$ wt wood. These results are not surprising since the $10 \%$ decomposition point in the first three samples (virgin wood, $80 \% \mathrm{wt}$, and $50 \% \mathrm{wt}$ wood) all correspond to temperatures for the degradation of cellulose while the $10 \%$ decomposition point for the $30 \% \mathrm{wt}$ wood corresponds to a temperature that includes other wood components. One would expect the activation energy for the combustion of cellulose to increase slightly in the first three samples since the pretreating in the oven has already completed the lower energy cellulose combustion reactions but the kinetics are still from the predominately cellulose containing region. In contrast, the $30 \% \mathrm{wt}$ sample is comprised of char from the cellulose and other wood components. The $10 \%$ decomposition point of this sample is thus measuring the kinetics of a completely different set of reactions. The kinetic parameters found for the virgin wood agree with those found by previous workers (Table 2).

Table 1. Kinetic parameters calculated from TGA and DSC data.

\begin{tabular}{|l|c|c|c|c|c|c|}
\hline & \multicolumn{3}{|c|}{ TGA } & \multicolumn{3}{c|}{ DSC } \\
\hline & $\mathbf{E ~ ( k J / g ) ~}$ & A (1/min) & $\mathbf{R}^{2}$ & $\mathbf{E ~ ( k J ) ~}$ & A (1/min) & $\mathbf{R}^{2}$ \\
\hline $\begin{array}{l}\text { Virgin } \\
\text { Wood }\end{array}$ & $170 \pm 23$ & $1.2 \pm 0.2 \times 10^{15}$ & 0.9642 & $\begin{array}{l}146 \pm 3 \\
169 \pm 8\end{array}$ & $\begin{array}{l}8 \pm 5 \times 10^{12} \\
5 \pm 7 \times 10^{13}\end{array}$ & $\begin{array}{l}0.9994 \\
0.9958\end{array}$ \\
\hline $\begin{array}{l}80 \% \mathrm{wt} \\
\text { wood }\end{array}$ & $188 \pm 14$ & $7.5 \pm 0.6 \times 10^{16}$ & 0.9884 & $212 \pm 33$ & $5 \pm 80 \times 10^{17}$ & 0.9887 \\
\hline $\begin{array}{l}50 \% \mathrm{wt} \\
\text { wood }\end{array}$ & $219 \pm 2$ & $3.86 \pm 0.04 \times 10^{19}$ & 0.9998 & $245 \pm 18$ & $1 \pm 4 \times 10^{23}$ & 0.953 \\
\hline $\begin{array}{l}30 \% \mathrm{wt} \\
\text { wood }\end{array}$ & $182 \pm 10$ & $4.1 \pm 0.2 \times 10^{14}$ & 0.9941 & N/A & N/A & N/A \\
\hline
\end{tabular}


Table 2. Literature values for the kinetic parameters for combustion of cellulosic materials.

\begin{tabular}{|l|l|l|l|l|}
\hline \multicolumn{1}{|c|}{ Investigator } & \multicolumn{1}{c|}{ Material } & \multicolumn{1}{c|}{ Method } & \multicolumn{1}{c|}{ E (kJ) } & \multicolumn{1}{c|}{ A (1/min) } \\
\hline Rogers and Ohlemiller [16] & $\begin{array}{l}\text { Cellulosic insulation } \\
\text { 1st reaction (2nd reaction) }\end{array}$ & TGA & $174(163)$ & $\begin{array}{l}7 \times 10^{14} \\
\left(4 \times 10^{10}\right)\end{array}$ \\
\hline Rogers and Ohlemiller [16] & $\begin{array}{l}\text { Cellulosic insulation } \\
\text { 1st reaction (2nd reaction) }\end{array}$ & DSC & $174(164)$ & $\begin{array}{l}6 \times 10^{14} \\
\left(3 \times 10^{11}\right)\end{array}$ \\
\hline Kaloustian [21] & $\begin{array}{l}\text { Cellulose from plant } \\
\text { materials }\end{array}$ & TGA & $186 \pm 4$ & \\
\hline Vecchio [22] & $\begin{array}{l}\text { Average of five wood } \\
\text { species }\end{array}$ & DSC & 135 & $4 \times 10^{13}$ \\
\hline McNaughton [23] & Hard Maple & $\begin{array}{l}\text { Isothermal } \\
\text { TGA }\end{array}$ & 138 & 50 \\
\hline Othman and Shamsuddin [25] & Coal (average of 3 types) & TGA & 27 & \\
\hline
\end{tabular}

\section{DIFFERENTIAL SCANNING CALORIMETRY}

\section{Test Procedure}

DSC measurements were performed on a Thermal Analysis Model 2910 differential scanning calorimeter following the procedures described in ASTM method E 698-01 [24]. The instrument was calibrated with indium. A representative sawdust sample of approximately $5 \mathrm{mg}$ was hermetically sealed in an aluminum sample container and equilibrated at $80^{\circ} \mathrm{C}$ before heating under a dried air atmosphere from 80 to $550{ }^{\circ} \mathrm{C}$ using linear heating rates of 1,2,5, and $10 \mathrm{~K} / \mathrm{min}$. An empty sample container was placed in the reference compartment. The data were analyzed according to the ASTM method with the alternative method used to calculate the activation energies.

\section{Results}

The DSC results for the virgin wood, 50 weight $\%$ and 30 weight $\%$ samples with heating rates of $10 \mathrm{~K} / \mathrm{min}$ are shown in Fig. 6. The data were normalized to the initial weight (i.e., before the pretreating) for each sample. The most obvious changes in the calorimetric results on pretreating the wood is a decrease in the endothermic peak at approximately $150^{\circ} \mathrm{C}$ and first a temperature shift then decrease of the exothermic peaks above $300^{\circ} \mathrm{C}$. The low temperature endotherm is most likely due to the decomposition of the cellulose to form char. The steady decrease in this peak caused by the pretreating of the wood reflects the fact that these char-forming reactions occurred in the oven during the pretreating. This observation is consistent with the visual appearance of the samples which showed an increased brittleness and darker color as samples were heated for a longer time. The $30 \%$ sample was completely black and could be easily reduced to powder by a mortar and pestle. The first exothermic peak (approximately $300^{\circ} \mathrm{C}$ in the virgin wood sample) is due to the oxidation reactions of the cellulose fragments while the second exothermic peak (approximately $400^{\circ} \mathrm{C}$ in the virgin wood sample) is due to the oxidation of the cellulose char and other wood components polysaccharides [17-21]. The observation that the first exothermic peak appears to shift temperature and increase slightly in magnitude as compared to the virgin wood is most likely explained by the reduction in magnitude of the overlapping lower temperature exothermic peak and not to an actual change in the peak itself. The DSC data is consistent with the TGA data in supporting the conclusion that the same sequence of reactions are occurring in the oven during pretreating as in the DSC during the experimental run. The virgin wood sample shows the expected magnitudes of the energy changes due to decomposition and then oxidation of the biopolymers. In comparison, the 50\% weight samples shows that most of the decomposition has occurred by the oxidation reactions have not progressed appreciable and the $30 \%$ weight sample shows that the decomposition reaction and oxidation reactions are almost entirely completed. It should be noted that no addition exothermic reaction that can be assigned to the presence of pyrophoric carbon has appeared. 


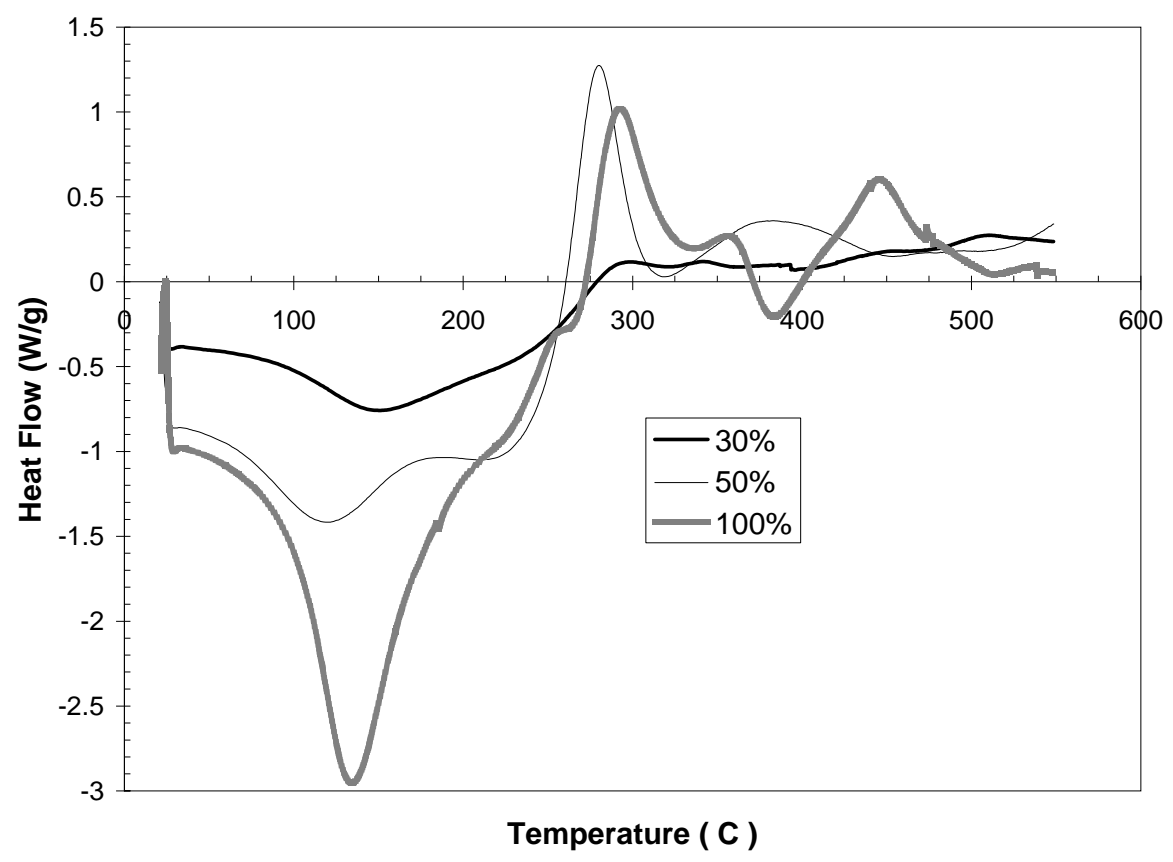

Fig. 6. Normalized DSC results for a virgin wood and 30 and 50 weight $\%$ samples with heating rates of $10 \mathrm{~K} / \mathrm{min}$.

The activation energy (E) and Arrhenius pre-exponential factor were calculated from this data using the method described in ASTM E 698. The peak temperature for the initial reaction was determined and plotted as $-\ln \left(\beta / \mathrm{T}^{2}\right)$ vs. $1 / \mathrm{T}(\mathrm{K})$ (Fig. 7). The kinetic parameters for both of the two lowest energy exothermic reactions were calculated for the virgin wood samples. Poorly defined peaks in the $30 \%$ sample precluded the accurate calculation of the kinetic parameters.

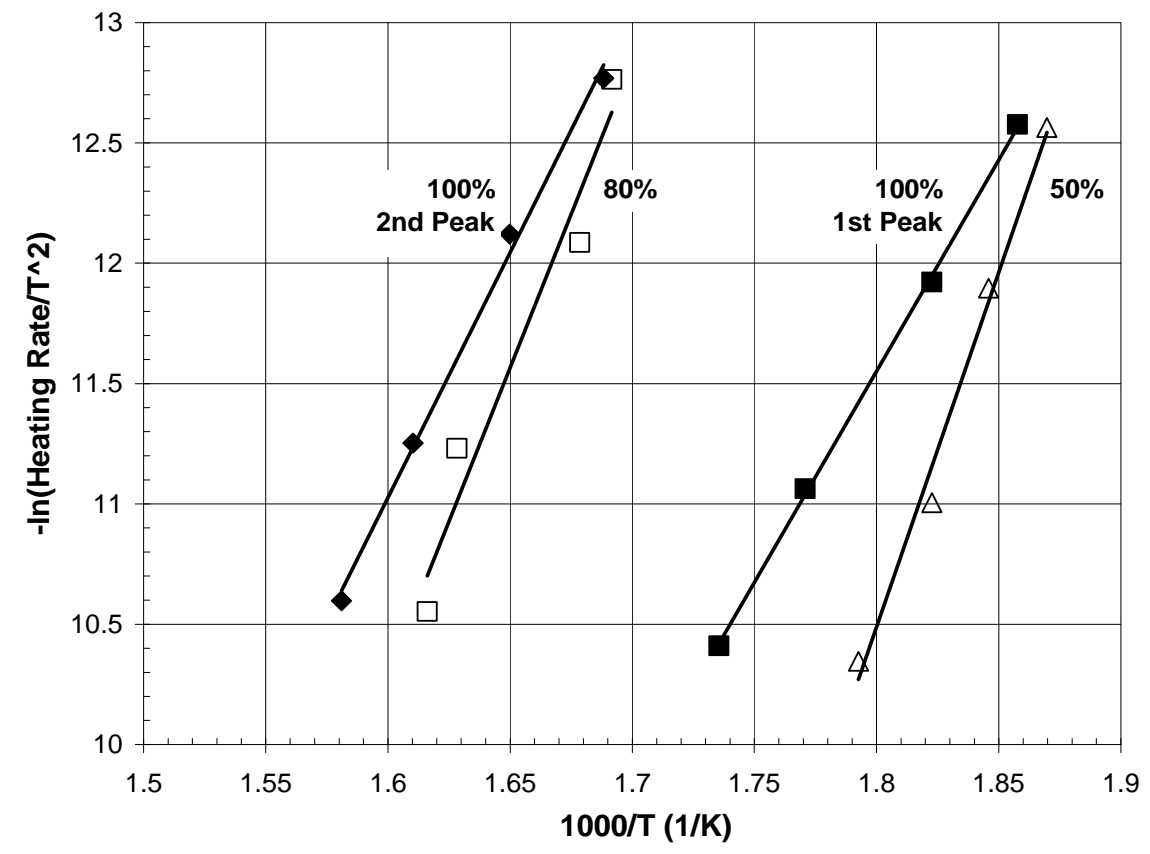

Fig. 7. The Arrhenius plots for the DSC data for virgin wood and 50 and 80 weight $\%$ samples. 
The activation energy was calculated according to ASTM method 698-01 from the Eq. 3.

$$
\mathrm{E}=(\mathrm{R}) * \Delta\left(-\log \beta / \mathrm{T}^{2}\right) / \Delta(1 / \mathrm{T})
$$

and the pre-exponential factor was calculated using Eq. 4.

$\mathrm{A}=\left(\beta E R \mathrm{e}^{\mathrm{E} / \mathrm{RT}}\right) / \mathrm{RT}^{2}$

The rate constants, k, for these reactions were then calculated from the Arrhenius Eq. 5.

$\mathrm{k}=\mathrm{Ae}^{-\mathrm{E} / \mathrm{RT}}$

The standard deviations were calculated from the observed standard deviation of the data and do not include the inherent error introduced by the ASTM method. The results are summarized in Table 1. For comparison, previously measured literature values are summarized in Table 2 .

The magnitude of the activation energies and pre-Arrhenius factors for the first exotherm are consistent with those measured by the TGA method with both values increasing slightly as the wood is pretreated to the $80 \%$ and $50 \%$ weight samples (see Table 1). The activation energies of the first and second exothermic reactions in the virgin wood (146 and $169 \mathrm{~kJ}$, respectively) are also consistent with literature values. Rogers and Ohlemiller [16] have reported the activation energies for the two exothermic reactions in cellulosic insulation to be 174 and $164 \mathrm{~kJ}$, while Vecchio et al. [22] has reported the average activation energy for the first exothermic reaction in five different wood species to be $135 \mathrm{~kJ}$. The measured pre-Arrhenius factors for the virgin wood $\left(8 \pm 5 \times 10^{12}\right.$ and $\left.5 \pm 7 \times 10^{13} \mathrm{~min}^{-1}\right)$ are within two orders of magnitude of those measured by Rogers and Ohlemiller [16] for the cellulosic insulation $\left(6 \times 10^{14}\right.$ and $\left.3 \times 10^{11} \mathrm{~min}^{-1}\right)$. The observed differences between our values and those of the cellulosic insulation most probably reflect both the different material and inherent errors is the method of approximating the pre-Arrhenius factor.

The most interesting observation in the DSC data is that the kinetic parameters for the second exothermic peak in the virgin wood $\left(\mathrm{E}=169 \pm 8 \mathrm{~kJ}, \mathrm{~A}=5 \pm 7 \times 10^{13} \mathrm{~min}^{-1}\right)$ are comparable to those measured by TGA for $30 \%$ weight sample $\left(E=182 \pm 10 \mathrm{~kJ}, \mathrm{~A}=4.1 \pm 0.2 \times 10^{14} \mathrm{~min}^{-1}\right)$. This correlation is consistent with the observed TGA curves which show that the 30 weight $\%$ sample curve superimposes the virgin wood curve after the first region of oxidation reactions has been completed. In other words, the kinetic parameters calculated from the $10 \%$ decomposition point of the $30 \mathrm{weight} \%$ samples should correspond to the kinetic parameters from the second exothermic peak in the virgin wood if the same series of reactions are occurring during both the moderate oven heating and the heating in the TGA/DSC experiments. In summary, the correlation of the TGA data from the $30 \%$ sample with the second exothermic peak in the virgin wood strongly supports the absence of any new reaction intermediates, such as pyrophoric carbon, in the charring process caused by prolonged exposure to moderate heat.

The absence of indications of enhanced self-heating properties in pretreated wood samples studied here stand in stark contrast to the prior results of Hartman et al. [12] in which clear and qualitative changes in the TGAs and DSCs were observed when true enhanced self-heating behavior was induced by the addition of cerium nitrate to cotton toweling. Cerium nitrate reduced the minimum heat flux for ignition from 7.5 to $3 \mathrm{~kW} / \mathrm{m}^{2}$, and the changes in self-heating properties were apparent in TGA, DSC, as well as via oven testing.

\section{CONCLUSION}

The data from the cone calorimeter, TGA, and DSC experiments do not support the presence of pyrophoric carbon in the pretreated wood samples. The results from all of these techniques are consistent with the virgin wood and thermally pretreated wood samples following the same combustion mechanism with the thermally pretreated samples starting further along the pathway. The cone calorimeter results show that the minimum flux needed for ignition was not affected by the thermal pretreatment of the samples, but the time to ignition was shortened for the thermally pretreated samples that were exposed to a high enough heat flux in the calorimeter. The reduction in heating time is expected since a smoldering ignition mechanism 
requires charring as the first step. Since this step has already been accomplished in whole or in part in the thermally pretreated materials, the ignition can occur more quickly. In addition, the thermal inertia of the thermally pretreated wood is lowered.

The TGA data in Fig. 4 demonstrated quite convincingly that the lower temperature $\left(<300^{\circ} \mathrm{C}\right)$ combustion reactions in the thermally pretreated samples were partially completed in the oven pretreatment, but that the higher temperature combustion reactions $\left(300^{\circ} \mathrm{C}\right.$ to $\left.500^{\circ} \mathrm{C}\right)$ were identical in the virgin and thermally pretreated samples. The DSC results summarized in Fig. 6 support the TGA data by showing a significant reduction in the endothermic combustion reactions that occur under $300^{\circ} \mathrm{C}$ in samples that had been exposed to thermal pretreatment, but no systematic change in the exothermic combustion reactions that occur above $300^{\circ} \mathrm{C}$. This conclusion is consistent with previous work. Hshieh and Richards [26] have shown that pretreating cottonwood resulted in the decomposition of the hemicelluloses (DTG inflection at about $290^{\circ} \mathrm{C}$ ) but not the decomposition of the celluloses (DTG peak at about $325^{\circ} \mathrm{C}$ ) and that this decomposition of hemicellulose was complete after 30 days of heating in air at $150^{\circ} \mathrm{C}$. In addition, the kinetic parameters calculated from our TGA and DSC data both support the hypothesis that the charring observed in the oven pretreatment is the products from the low temperature decomposition reactions completed in the early stages of combustion and not a sign of the formation of a high energy pyrophoric species. The activation energy (barrier) of the initial reactions observed in the wood samples was found to increase with the pretreatment heating time, thus showing that the lower energy reactions were completed in the oven before the TGA or DSC experiments were begun.

Acknowledgments: Thanks to M. Gratkowski and J. Sikorski for assistance in cone calorimeter experiments.

\section{REFERENCES}

[1] Cuzzillo, B.R. (1997), Pyrophoria, PhD Dissertation, Univ. of California at Berkeley, Berkeley, CA.

[2] Cuzzillo, B.R., and Pagni, P.J., (1999). The Myth of Pyrophoric Carbon, Fire Safety Science 6: 301-312. http://dx.doi.org/10.3801/IAFSS.FSS.6-301

[3] Babrauskas, V., Gray, B.F., et al., (2007), Prudent Practices for the Design and Installation of Heat-producing Devices Near Wood Materials, Fire and Materials 31: 125-135. http://dx.doi.org/10.1002/fam.929

[4] Bilbao, R., Mastral, J.F., Aldea, M.E., Ceamanos, J., Betran, M., and Lana, J.A., (2001), Experimental And Theoretical Study Of The Ignition And Smoldering Of Wood Including Convective Effects, Combustion and Flame, 126(1-2): 1363-1372. http://dx.doi.org/10.1016/S0010-2180(01)00251-6

[5] Spearpoint, M.J., and Quintiere, J.G., (2001), Predicting the Piloted Ignition of Wood in the Cone Calorimeter using an Integral Model, Fire Safety $J$ 36(4): 391-415. http://dx.doi.org/10.1016/S0379-7112(00)00055-2

[6] Spearpoint, M.J., (1999), Predicting the Ignition and Burning Rate of Wood in the Cone Calorimeter using an Integral Model, Master's thesis, University of Maryland.

[7] Boonmee N, Quintiere J.G. (2002), "Glowing and Flaming Autoignition of Wood," Twenty-ninth Symposium (International) on Combustion, The Combustion Institute, pp. 289-296. http://dx.doi.org/10.1016/S1540-7489(02)80039-6

[8] Boonmee N, Quintiere J.G. (2005), Glowing Ignition of Wood: The Onset of Surface Combustion, Thirtieth Symposium (International) on Combustion, The Combustion Institute, 2005, pp. 2303-2310. http://dx.doi.org/10.1016/j.proci.2004.07.022

[9] Lim, S., Chew, M. (2007), The Ignition of Green and Preburn Wood by Radiation, Fire and Materials Conference 2007, Interscience Communications.

[10] Gratkowski, M., Dembsey, N., Beyler, C. (2006), Radiant Smoldering Ignition of Plywood, Fire Safety J. 41: 427-443. http://dx.doi.org/10.1016/j.firesaf.2006.03.006 
[11] Bowes, P.C. (1984), Self-Heating: Evaluating and Controlling the Hazards, Her Majesty's Stationery Office, London.

[12] Hartman, J.R., Waters, C.A., Beyler, C.L. (2007), An Evaluation of the Self-heating Hazards of Cerium (IV) Nitrate Treated Towels Using Differential Scanning Calorimetry and Thermogravimetric Analysis, Fire and Materials 31: 359-371. http://dx.doi.org/10.1002/fam.941

[13] Beyler, C.L., Fay, T., Gratkowski, M., Campbell, B., Hartman, J.R. (2006), Ignition Studies of Cerium Nitrate Treated Towels, Fire and Materials 30: 223-240. http://dx.doi.org/10.1002/fam.908

[14] ASTM E 1354-02 (2002), Standard Test Method for Heat and Visible Smoke Release Rates for Materials and Products Using an Oxygen Consumption Calorimeter, ASTM International, West Conshohocken, PA.

[15] ASTM E 1641-99, (1999), Standard Test Method for Decomposition Kinetics by Thermogravimetry, ASTM International, West Conshohocken, PA.

[16] Rogers, F.E., and Ohlemiller, T.J., (1980), Cellulosic Insulation Material I. Overall Degradation Kinetics and Reaction Heats, Combustion Science and Technology 24: 129-137. http://dx.doi.org/10.1080/00102208008952431

[17] Wiedemann, H.G., and Bayer,G., (1986), Thermoanalytical study on ancient materials and light it sheds on the origin of letters and words, Thermochimica Acta 100: 283-314. http://dx.doi.org/10.1016/0040-6031(86)87062-9

[18] Tomassetti, M., Campanella, L., Tomellini, R.; Meucci, C., (1987), Thermogravimetric Analysis of Fresh and Archeological Waterlogged Woods, Thermochimica Acta 117: 297-315. http://dx.doi.org/10.1016/0040-6031(87)88124-8

[19] Campanella, L., Tomassetti, M., (1991). Thermoanalysis of Ancient, Fresh, and Waterlogged Woods, Journal of Thermal Analysis 37: 1923-1932. http://dx.doi.org/10.1007/BF01912224

[20] Tsujiyama, S.-i., Miyamori, A., (2000), Assignment of DSC Thermograms of Wood and its Components, Thermochimica Acta 351: 177-181. http://dx.doi.org/10.1016/S0040-6031(00)00429-9

[21] Kaloustian, J., Pauli, A.M., Pastor, J., (2001). Kinetic Study of the Thermal Decompositions of Biopolymers Extracted from Various Plants, Journal of Thermal Analysis and Calorimetry 63: 7-20. http://dx.doi.org/10.1023/A:1010199831895

[22] Vecchio, S., Luciano, G., Franceschi, E. (2006), Exploration Kinetic Study on the Thermal Degradation of Five Wood Species for Applications in the Archeological Field, Annali di Chimica 96: 715-725. http://dx.doi.org/10.1002/adic.200690074

[23] McNaughton, G. C. (1945), Ignition and Charring Temperatures of Wood, Wood Products 50(2): $21-22$.

[24] ASTM E 698-01, (2001). Standard Test Method for Arrhenius Kinetic Constants for Thermally Unstable Materials, ASTM International, West Conshohocken, PA.

[25] Othman, N.F., and Shamsuddin, A.H., (2003), Coal Combustion Studies using Thermogravimetric Analysis, Jurnal Mekanikal 15: 97-107.

[26] Hshieh, F.Y., and Richards, G.N., (1989). The Effect of Preheating of Wood on Ignition Temperature of Wood Char, Combustion and Flame 80: 395-398. http://dx.doi.org/10.1016/0010-2180(90)90115-8 